\title{
Cri Du Chat Syndrome: Dental Management and Case Report
}

Raissa Christine Oliveira de Carvalho, Larissa Conrado da Silva, Flávia Silva Pires, Aline Silveira dos Santos Menezes, Mônica Almeida Tostes and Viviane Cancio*

Paediatric Dentistry Department, School of Dentistry, Fluminense Federal University, Rua Mário Santos Braga, $n^{\circ} 30$ - Campus Valonguinho, Centro, Niterói, RJ, CEP 24040-110, Brazil

${ }^{*}$ Corresponding author: Viviane Cancio, Paediatric Dentistry Department, School of Dentistry Universidade Federal Fluminense / Faculdade de Odontologia - Rua Mário Santos Braga, Campus Valonguinho, Centro, Niterói, RJ, CEP 24040-110, Brazil, Tel: +55 21 2629 9829; E-mail: vicancio@ig.com.br

Recieved Date: May 28, 2018; Accepted Date: Jun 20, 2018; Published Date: Jun 20, 2018

Copyright: (c) 2017 de Carvalho RCO, et al. This is an open-access article distributed under the terms of the Creative Commons Attribution License, which permits unrestricted use, distribution, and reproduction in any medium, provided the original author and source are credited.

\begin{abstract}
Cri du chat Syndrome (CdCS) is a rare genetic condition with an incidence of 1:50,000 live births. It is a severe disease resulting from a deletion of the short arm of chromosome 5 and is characterized by intellectual disabilities and delayed physical development. The basic medical disorder includes dysmorphic facies, mental retardation, and a striking catlike cry in infancy. Because of significant oral anomalies and difficulty in behaviour management, the syndrome is of particular interest to dental practitioners. The aim of this paper was to report a case of a 12-year-old patient with CdCS referred to a paediatric dental clinic for dental treatment.
\end{abstract}

Keywords: 5 p deletion; Cri du chat syndrome; Paediatric dentistry; Etiology; Classification; Analysis; Diagnosis

\section{Introduction}

Cri du chat syndrome (CdCS), discovered by Lejeune et al. in 1963 [1], is a genetic disease resulting from a deletion of the short arm of chromosome $5(5 \mathrm{p}-)$. It is a rare disease with an incidence of 1:50,000 live-born infants [1]. The main character of this syndrome is a highpitched catlike cry (hence the name of the syndrome), which was thus described by Grouchy and Turleau in 1977 [2], due to malformation of the larynxes of children with this syndrome. However, it is believed that with advancing age, such sound becomes less characteristic, making it difficult to diagnose this condition [3]. CdCS is characterized by intellectual disabilities and delayed physical development, including abnormalities of the airways [4]. The clinical features at birth are low weight, microcephaly, round face, large nasal bridge, hypertelorism, epicanthal folds, downward slanting palpebral fissures, down-turned corners of the mouth, low-set ears, micrognathia, and abnormal dermatoglyphics (transverse flexion creases) [5]. Diagnosis of this syndrome is defined by the clinical characteristics and examination of the cytogenetic-affected child, with a guideline available for the parents [6]. Patients with this syndrome may present orofacial anomalies, including mandibular microretrognathia, dental biprotrusion, dental malocclusions, high but rarely cleft palate, anterior open bite, poor oral hygiene, enamel hypoplasia, generalized chronic periodontitis, and retardation of tooth eruption [6,7]. Taking into consideration the relevance of CdCS, the objective of this study was to report the dental treatment performed on a patient with a CdCS diagnosis.

\section{Case Report}

A 12-year-old male patient diagnosed with CdCS attended the clinic of the Acolher/PNE project at Fluminense Federal University for dental treatment. The patient's mother sought dental care because the patient, who has a speech disability, showed pain in the lower region of the teeth. The patient used to show his mother where it hurts by placing his hand on his face, near the acking teeth. Anamnesis and clinical examination were performed. The patient's mother reported that she was 25 years old when she became pregnant and had a pregnancy without complications or the use of medicine. The mother also reported no presence of congenital anomalies in other family members.

The medical history revealed hospitalization for bacterial pneumonia for five months, a seizure, anaemia, and a tracheostomy. The patient uses drugs such as levothyroxine sodium (once a day) for treatment of congenital hypothyroidism and risperidone (once a day) for anxiety control and altered behaviour; he started taking these medications at three years old. The manufactures claim these medications have no side effects in oral cavity. In addition, the patient undergoes occupational therapy as a means of cognitive development and presents a deficit of learning and communication; however, he hears in a normal tone.

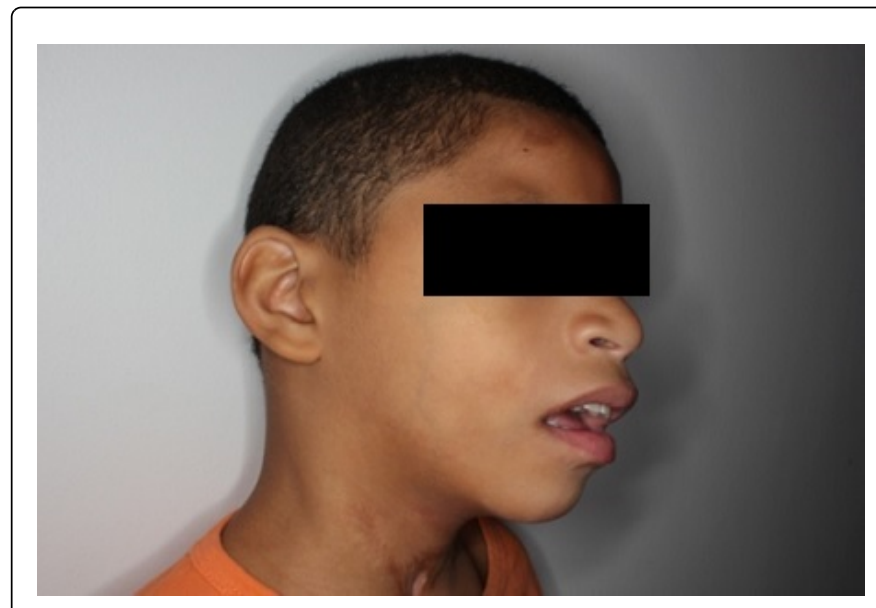

Figure 1: Side view of patient's face.

The patient's dysmorphic features included microcephaly, a broad forehead, a depressed nasal bridge, bilateral low-set ears, a high-arched 
Citation: de Carvalho RCO, da Silva LC, Pires FS, Menezes ASS, Tostes MA, et al. (2018) Cri Du Chat Syndrome: Dental Management and Case Report. Dentistry 8: 496. doi:10.4172/2161-1122.1000496

Page 2 of 3

palate, a convex facial profile with mandibular microretrognathia, and an anterior open bite (Figure 1).

Clinical examination revealed white demineralized spot were found in the cervical portion of his teeth, supragingival dental calculus on the buccal and palatine faces of the lower incisors and mobility grade I in the lower central incisors with the presence of gingival recession (Figures 2 and 3).

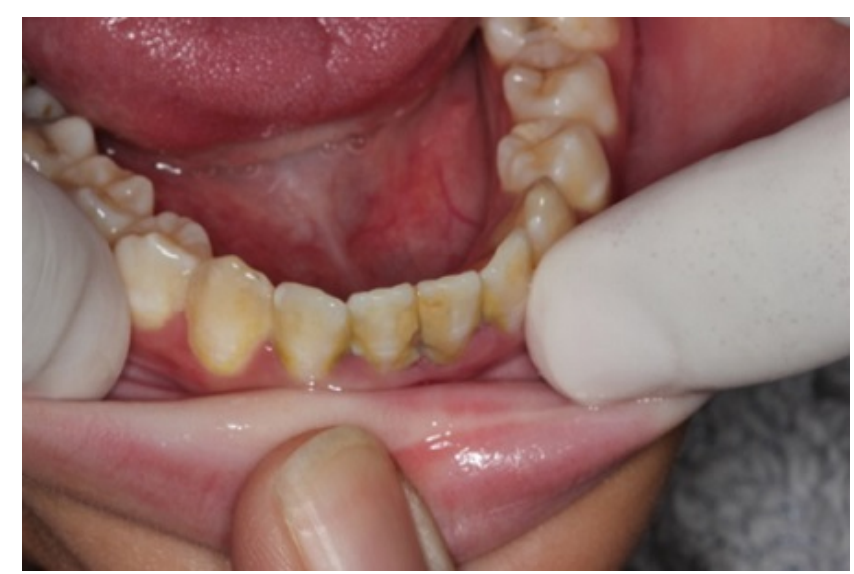

Figure 2: Supragingival dental calculus.

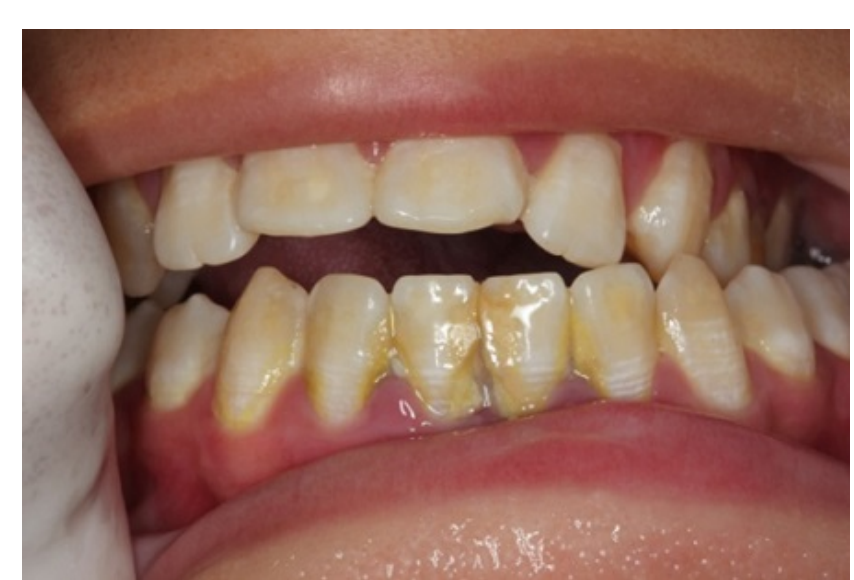

Figure 3: The lower central incisors with presence of gingival recession.

During the first visit, the child and his mother received instructions on how to perform effective oral hygiene as a strategy to reduce gingivitis. The patient received a toothpaste tube containing $90 \mathrm{~g}$ of Colgate $^{\odot}$ herbal toothpaste (Colgate - Palmolive, Brazil) containing calcium carbonate, chamomile, sage, myrrh eucalyptus, and sodium monoflurophosphate. The mother was instructed to apply a $15-\mathrm{mm}$ length of the toothpaste on the brushing surface of a toothbrush and brush three times a day (morning, after dinner, and night) for a period of 5-10 min. A supervised brushing was performed in order to instruct the mother on how to perform this brushing. The patient's mother was also instructed to reduce the consumption of sugar.

After one week, the patient showed better gingival condition, and there was a incisor swith increase in dental mobility. Dental treatment was performed with the mother holding the patient in her arms. In the first three appointments, supragingival tartar was scraped, due to difficulty in conditioning the child in the clinical environment, 3 appointments were made. In addition, radiograph bitewings were taken of the left and right molars for diagnosis of caries of the first permanent maxillary right molar, first permanent mandibular right molar, and second permanent maxillary right molar. Total removal of caries was performed in the first permanent mandibular right molar with absolute isolation and restoration with photopolymerized composite resin for sealing of the cavity (Figures 4 and 5). The patient received only local anesthesia because oral sedation or general anesthesia were not an option due to legal issues in Brazil.

The patient is being supervised and attends follow up appointments every 6 months.

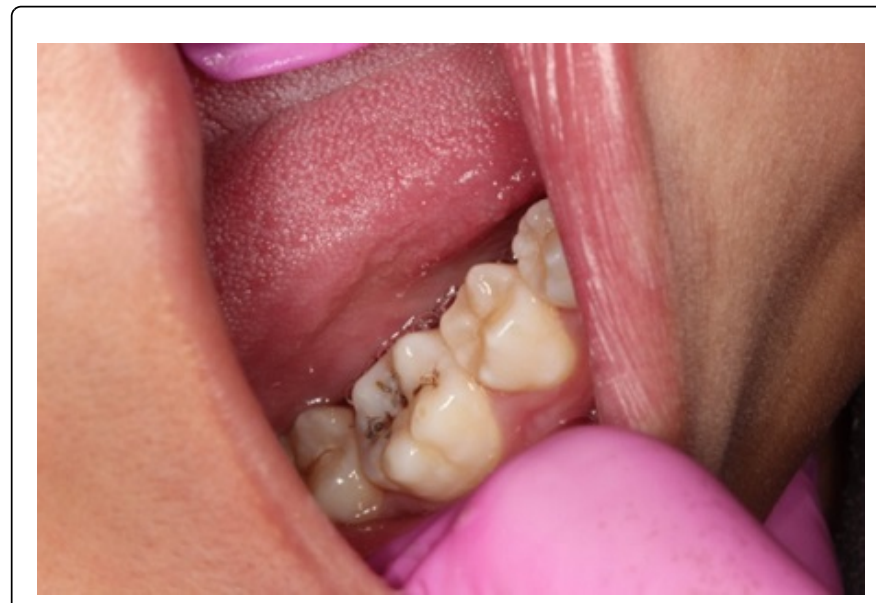

Figure 4: Decayed first permanent mandibular right molar.

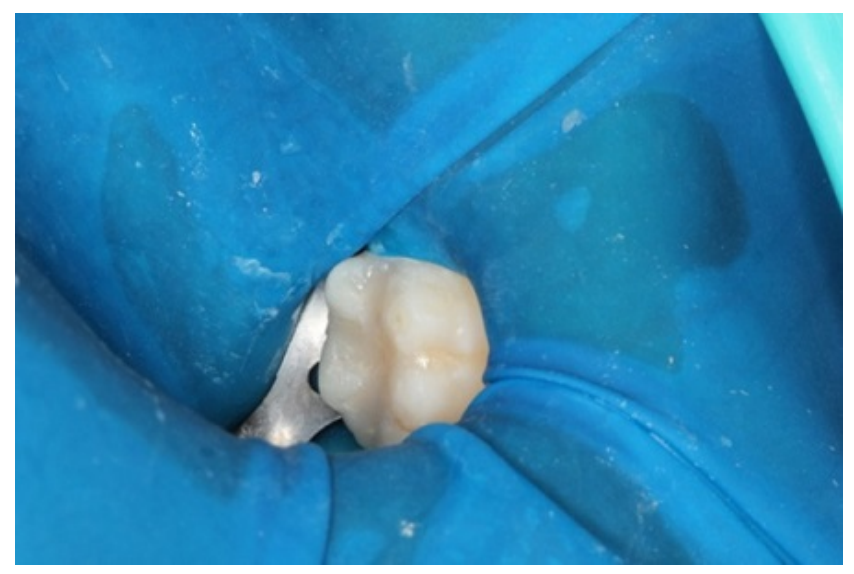

Figure 5: Tooth after restoration with composite resin.

\section{Discussion}

CdCS is a rare genetic disorder linked to the short arm of chromosome 5p, which must be considered and studied by health professionals. It is uncommon in dental practice; therefore, little is known about the best way to treat a patient with this syndrome. The 
Citation: de Carvalho RCO, da Silva LC, Pires FS, Menezes ASS, Tostes MA, et al. (2018) Cri Du Chat Syndrome: Dental Management and Case Report. Dentistry 8: 496. doi:10.4172/2161-1122.1000496

Page 3 of 3

patient in this case report presents orofacial characteristics in accordance with previous descriptions found in the literature [6-8].

The clinical features at birth are low weight (mean weight $2614 \mathrm{~g}$ ), microcephaly (mean head circumference $31.8 \mathrm{~cm}$ ), round face $(83.5 \%)$, large nasal bridge (87.2\%), hypertelorism $(81.4 \%)$, epicanthal folds (90.2\%), downward slanting palpebral fissures $(56.9 \%)$, down-turned corners of the mouth $(81.0 \%)$, low-set ears $(69.8 \%)$, micrognathia (96.7\%), abnormal dermatoglyphics (transverse flexion creases, 92\%), and the typical cry (95.9\%) [9]. The following features develop with age: the face becomes long and narrow $(70.8 \%)$; the supra-orbital arch becomes prominent $(31.0 \%)$; the philtrum shortens $(87.8 \%)$; the lower lip becomes full (45.2\%); dental malocclusion develops (open bite) (75.0\%) (Figure 1); palpebral fissures tend to become horizontal (70.2\%); divergent strabismus is frequent (44.7\%); metacarpi $(82.6 \%)$ and metatarsi (75.0\%) are short, resulting in small hands and feet; and prematurely grey hair may be observed (30.4\%) [9].

The typical cry is probably due to abnormalities of the larynx, such as hypoplasia, narrowing, and asymmetric vocal cords and epiglottis, which may be small, hypotonic, and flaccid, in addition to neurological impairments. These abnormalities, combined with micrognathia, changes in hard and soft palates, may contribute to the difficulty in tracheal intubation [10].

The diagnosis is primarily clinical and confirmed by cytogenetic analysis, and in dubious cases, it is necessary to perform molecular tests such as fluorescence in situ hybridisation (FISH) to accurately identify the region of the affected chromosome [11].

CdCS treatment is based mainly on early rehabilitation strategies (physiotherapy, speech therapy, and occupational therapy), prevention of complications, and correction of malformations. Audiometric examination and extra-calendar vaccination are recommended [11].

Behavioural problems must be taken in evalution, especially with this kind of patient. He could only be handled with physical restrain, previously approved by his mother in a consent form. Before every appointment he had to take risperidone and could only hold his mouth open with help from a pediatric mouth opener. Still, all planned dental care was provided.

The oral hygiene of the patient with this syndrome is very poor and hard be associated the difficulty that the patient has to open his mouth [12]. It is necessary to strengthen the parents' methods for ensuring cleanliness and good oral hygiene. Specific therapies for these patients contribute to the development of these methods, in addition to working with the families to gain greater knowledge on the subject
$[5,6]$. Thus, CdCS patients can gain greater progress at all levels, whether in health or society.

\section{Conclusion}

It is important for health professionals to know that the principal clinical characteristics of CdCS can be routed to specific treatments as early as possible. In addition, it is necessary to expand the dissemination of research in the dental field to gain a better understanding and knowledge of this subject. Finally, it is important to know the correct approach for the conditioning and treatment of such patients in search of the best means for therapeutic intervention.

\section{References}

1. Lejeune J, Lafourcade J, Berger R, Vialatte J, Boeswillwald M, et al. (1963) 3 cases of partial deletion of the short arm of a 5 chromosome. C R Hebd Seances Acad Sci. 257: 3098-102.

2. de Grouchy J, Turleau C (1977) Atlas desmaladies Cromossomiques. Paris: Expansion Scientifique Française.

3. Drago R, Burgos VPB, Santos CR (2014) A criança com Síndrome CriDu-Chat na escola comum: um estudo de caso. Revista Educação Especial 27: 391-402.

4. Machado N, Cecílio RA, Takeshi ST, Lima MO, LazoOsório RA (2007) Principais características clínicas da síndrome Cri-Du-Chat: revisão de literatura. Encontro Latino Americano De Iniciação Científica 11: 1668-1671.

5. Mainardi PC (2006) Cri du chat syndrome.Orphanet Journal of Rare Diseases 1: 33 .

6. Köylüoglu ZI, Esma Y, Nur BG, Ercan M, Clark OA (2015) Oral manifestations of a patient with cri du chat $(5 \mathrm{p}-)$ syndrome. Jounal Pediatr Dent 3: 67-70.

7. Yáñez-Vico RM, Rodríguez-Caballero A, Iglesias-Linares A, GuerraLópez N, Torres-Lagares D, et al. (2010) Craniofacial characteristics in criduchat syndrome. Oral Surg Oral Med Oral Pathol Oral RadiolEndod 110: e38-44.

8. Wiedemann HR, Kunze J, Dibbern H (1992) Atlas de síndromes clínicas dismórficas. São Paulo: Manole.

9. Mainardi PC (2006) Cri du chat syndrome. Orphanet JRare Diseases: 1.

10. Santos KM, Rezende DC, Borges ZDO (2010) Manejo Anestésico de Paciente com Síndrome de Cri Du Chat (Miado do Gato). Relato de Caso. Revista Brasileira de Anestesiologia 60: 630-633.

11. Sampaio B, Guedes A, Areias A, Carvalho C (2008) Síndrome Cri du Chat - Caso Clínico. Nascer e Crescer 17: 37-39.

12. Pereira JT, Oliveira RS, Lindemann D, Araújo FB, Rodrigues JA (2013) Cridu chat syndrome: conservative dental treatment in an 8-year-old child. Stomatos 19: 44-52. 